\title{
The influence of personality and life events on subjective well-being from a life span perspective
}

\author{
Veronica Gomez ${ }^{\mathrm{a}, *}$, Franciska Krings ${ }^{\mathrm{b}}$, Adrian Bangerter $^{\mathrm{c}}$, Alexander Grob ${ }^{\mathrm{a}, *}$ \\ ${ }^{a}$ Faculty of Psychology, Department of Personality and Developmental Psychology, University of Basel, Missionsstrasse 60/62, 4055 Basel, Switzerland \\ ${ }^{\mathrm{b}}$ Faculty of Business and Economics HEC, University of Lausanne, Switzerland \\ ${ }^{\mathrm{c}}$ Institut de Psychologie du Travail et des Organisations, University of Neuchâtel, Switzerland
}

\section{A R T I C L E I N F O}

Available online $\mathrm{xxxx}$

\section{Keywords:}

Personality

Big Five

Life events

Subjective well-being

Life span

Age groups

\begin{abstract}
A B S T R A C T
We investigate the relation between personality (Big Five) and positive and negative life events as predictors of subjective well-being (SWB) in a sample of 766 young, middle-aged, and old adults. Analyses comprised data on personality, SWB, and reconstructed positive and negative life events. Results for the total sample indicate a strong relation between neuroticism and SWB, and an important influence of reconstructed life events on SWB with a stronger effect for negative as compared to positive events. Age differences in the prediction of SWB emerge for personality and life events: extraversion is only a predictor of SWB in young adults and the effect of neuroticism is more pronounced in old adults. Moreover, the influence of negative life events on SWB is stronger in young and middle-aged adults as compared to old adults. These results emphasize the need to study dispositional and situational variables across the life span in order to better understand the underlying mechanisms of SWB.
\end{abstract}

(c) 2008 Elsevier Inc. All rights reserved.

\section{Introduction}

To understand why people are happy and what the underlying causes of happiness are is of crucial importance for mankind and the major aspiration of research in subjective well-being (SWB). SWB is commonly understood as an umbrella term for life satisfaction, positive affect, and absence of negative affect (Lucas, Diener, \& Suh, 1996), and has been shown to be quite stable over the lifetime, although prone to minor changes after significant life events (Diener, Suh, Lucas, \& Smith, 1999). There is a large body of evidence suggesting that life circumstances and demographic factors fail to account for a substantial percentage of variance in SWB (for an overview see Diener et al., 1999; Lyubomirsky, Sheldon, \& Schkade, 2005). As a consequence, there has been a shift in SWB research away from the focus on external factors and demographics (bottom-up factors) to analyses of top-down processes, i.e. factors within the individual (e.g., Diener et al., 1999). However, despite the large impact of personality on SWB, other lines of research also show a substantial influence of life events on SWB. Thus, both considerations should be taken into account when trying to explain the psychological mechanism of SWB. In what follows, we will start by separately focusing on established evidence for the impact of personality and life events on SWB, before elaborating on their joint contributions to SWB. Finally,

\footnotetext{
* Corresponding authors. Fax: +416126706 61.

E-mail addresses: veronica.gomez@unibas.ch (V. Gomez), alexander.grob@ unibas.ch (A. Grob).
}

we suggest that the influence of personality and life events on SWB may vary across the life span as a function of age and propose an integrating approach covering these dimensions.

\subsection{Personality and $S W B$}

A broad range of studies has compellingly shown that personality is an important precursor of SWB (e.g., Costa \& McCrae, 1980; Diener, 1984; Diener \& Larsen, 1993; Diener \& Lucas, 1999; McCrae \& Costa, 1991; Myers, 1992; Myers \& Diener, 1995). In this regard, variance in SWB can be explained by the personality traits of neuroticism and extraversion (Costa \& McCrae, 1980), and personality has been demonstrated to substantially predict SWB 20 years later (Costa \& McCrae, 1984). As a consequence, many researchers have focused on the correlations between neuroticism, extraversion, and SWB (Chico-Libran, 2006; Headey \& Wearing, 1992; Lucas \& Fujita, 2000; Pavot, Diener, \& Fujita, 1990; Vittersø \& Nilsen, 2002; Watson \& Clark, 1992), finding a robust negative relationship between neuroticism and SWB, and a robust positive relationship between extraversion and SWB. Moreover, the association has consistently been shown to be stronger for neuroticism than for extraversion. In addition, conscientiousness and agreeableness also predict SWB (McCrae \& Costa, 1991). Therefore, focusing exclusively on neuroticism and extraversion does not reveal the full picture of relations between personality and SWB. Recently, Steel, Schmidt, and Shultz (2008) conducted a comprehensive meta-analysis and evaluated the associations between each personality factor and SWB including the effects on the different components of well- 
being (happiness, positive and negative affect, overall affect, and quality of life). Their findings support a strong relationship between neuroticism, extraversion, agreeableness, conscientiousness and all components of SWB, whereas openness to experience shows close associations with the SWB facets of happiness, positive affect, and quality of life. Moreover, results from multivariate meta-analytic regression indicate that up to $39 \%$ of the variance in SWB can be accounted for by personality factors (Steel et al., 2008), a much higher proportion than reported in a previous meta-analysis (DeNeve \& Cooper, 1998). Twin and adoption studies provide further evidence for the strong relationship between dispositional factors and SWB, and clearly suggest that genetic factors are more important than environmental influences. Indeed, genetic factors explain approximately $80 \%$ of the variance in long-term SWB, whereas environmental influences only affect mood states in the short term with no long lasting effect on SWB (Lykken \& Tellegen, 1996; Nes, Røysamb, Tambs, Harris, \& Reichborn-Kjennerud, 2006). Moreover, stability of SWB is supposed to be due to heritable dispositions represented by the personality facets of neuroticism and extraversion (Nes et al., 2006).

Thus, given the strong relationship between personality and SWB and assumptions about the stable character of personality across the life span (Costa \& McCrae, 1997; McCrae et al., 2000), the conclusion might be drawn that SWB should be as stable as personality over the lifetime. However, recent work demonstrates mean-level change in personality traits throughout the life course (Helson, Jones, \& Kwan, 2002; Roberts, Walton, \& Viechtbauer, 2006; Srivastava, John, Gosling, \& Potter, 2003). Moreover, panel studies document only moderate stability in individual SWB scores over time (Abbey \& Andrews, 1985; Campbell, Converse, \& Rodgers, 1976; Headey, Glowacki, Holmstrom, \& Wearing, 1985). For instance, a recent panel study revealed that although $34-38 \%$ of the variance in SWB can be accounted for by stable characteristics like personality, a substantial amount $(29-34 \%)$ is only moderately stable over time (Lucas \& Donnellan, 2007; for similar results see Ehrhardt, Saris, \& Veenhoven, 2000). Hence, SWB is relatively stable over time, but there is considerable space for change and instability that might be due to changes in life circumstances.

\subsection{Life events and SWB}

A great deal of research has been based on the assumption that environmental changes represented by positive and negative life events substantially influence SWB (Abbey \& Andrews, 1985; Block \& Zautra, 1981; Headey, Holmstrom, \& Wearing, 1984; Headey et al., 1985; Zautra \& Reich, 1983). Positive life events enhance SWB, and negative life events reduce it, whereas neutral life events have no effect (Grob, 1991). Moreover, it seems that individuals are able to manage one critical life event, but if they are faced with two or more critical life events within a five-year period their SWB decreases importantly (Grob, 1995). These findings are supported by Veenhoven's (1994) review, stating that people's levels of happiness are affected by positive and negative life events, especially if they represent major life transitions. Nevertheless, the major inconvenience of these studies is the fact that life events are treated as entirely exogenous. In fact, there is evidence that the same kind of event often happens to the same type of people, indicating that there may be a relation between personality and the type of life events people experience (Headey \& Wearing, 1989).

\subsection{Personality, life events, and SWB}

Attempts to focus on the overall interplay between personality, life events, and SWB started with Brickman and Campbell's (1971) article on adaptation and the resulting hedonic treadmill hypothesis. According to this theory, adaptation is an inevitable basic pro- cess and individuals return to baseline levels of SWB after experiencing even most extreme positive (win of a lottery) or negative (severe accident) life events (Brickman, Coates, \& Janoff-Bulman, 1978). Based on a longitudinal study, Headey and Wearing (1989) suggested that each person has equilibrium levels of life events and SWB to which they return dependent on their personalities. Life events only alter SWB when they exceed equilibrium levels. Moreover, they found that people scoring high in extraversion experience many (subjectively) positive events and those scoring high in neuroticism experience many (subjectively) negative events (for similar results see Magnus, Diener, Fujita, \& Pavot, 1993). In contrast, people scoring high in openness experience many events of both kinds (Headey, 2006; Headey \& Wearing, 1989). Therefore, the dynamic equilibrium model assumes stable levels of SWB depending on personality and life events, whereas the way individuals perceive life events (positive, negative, neutral) throughout their lives is in turn regulated by personality characteristics (Headey \& Wearing, 1989).

Although set point models of happiness have received substantial empirical support (e.g., Argyle, 1987; Costa \& McCrae, 1980; Diener, 1984; Headey \& Wearing, 1989; Suh, Diener, \& Fujita, 1996), there is still no consensus about whether the influence of life events goes beyond the effects of personality. In fact, adaptation level theories imply that the effect of life events is only temporary and that people always return to their individual baseline level of well-being (Brickman \& Campbell, 1971; Headey \& Wearing, 1989; Nes et al., 2006). However, some evidence suggests a substantial and long-term influence of life events on SWB. For example, Lu (1999) found that positive life events predict life satisfaction 2.5 years later. Moreover, panel studies show that for a significant life event like marriage, adaptation seems to occur on average within a couple of years, whereas for widowhood, adaptation is very slow and individuals only return to their baseline levels of life satisfaction after about 8 years (Lucas, Clark, Georgellis, \& Diener, 2003). After divorce (Lucas, 2005) or unemployment (Lucas, Clark, Georgellis, \& Diener, 2004) people do not return completely to their initial level of life satisfaction. Thus, for some respondents there are long lasting and permanent changes in life satisfaction as a consequence of specific life events (Lucas, 2005; Lucas et al., 2004). Also, changes in SWB can be substantial: people's life satisfaction after onset of a disability is significantly below the initial level and does not recover completely over time (Lucas, 2007a). Moreover, when revising the dynamic equilibrium model, Headey $(2006,2008)$ not only found that people scoring high in extraversion or neuroticism have permanent and substantial changes in SWB, but he also offered further support for a longer lasting influence of life events on life satisfaction: the more life events in the last two years compared to the individual average level of life events, the greater is the upward (if positive events) or downward (if negative events) change in life satisfaction (Headey, 2006). In sum, recent research has started questioning the absoluteness of set point models (Diener, Lucas, \& Scollon, 2006; Headey, 2006, 2008). The major claim is to consider the fact that some circumstances can cause a shift in SWB set points and that adaptation to life events is not a universal phenomenon that applies to all individuals in an analogous manner (Diener et al., 2006).

\subsection{The relation between personality, life events, and SWB from a life span perspective}

Two different perspectives should be taken into account when considering the relation between personality, life events and SWB from a life span perspective: On the one hand, personality traits are thought to be independent of environmental influences and stable across the life course (e.g., Costa \& McCrae, 1997; Lykken \& Tellegen, 1996; Nes et al., 2006) with negligible mean-level 
changes in personality after the age of 30 (Costa, Herbst, McCrae, \& Siegler, 2000; McCrae et al., 2000). Moreover, SWB is strongly related to personality (e.g., DeNeve \& Cooper, 1998; Steel et al., 2008). This leads to the implication that age effects do not play a role in determining SWB. On the other hand, recent studies increasingly question the stability of traits, providing support for plasticity in personality development across the life course, and demonstrating continuing mean-level change of personality traits in middle and even old age (Helson et al., 2002; Roberts et al., 2006; Srivastava et al., 2003). Hence, these studies suggest differences in the relation between personality and SWB across ages. Similarly, relations among personality and life events in the prediction of SWB may vary across the life span because of differing life circumstances and life experiences associated with different phases in life. Thus, as far as content of life experiences is concerned and also according to Havighurst's formulation of developmental tasks (1948) or Erikson's stage theory of psychosocial development (1980), people have different tasks to accomplish in different life stages and thus face different life events across the life span: for instance, events related to education in the first quarter of life, work-related events in the second and third quarter of life (including retirement in the third quarter), and health- and death-related events as well as more societal events in the last quarter of life (Grob, Krings, \& Bangerter, 2001). But more importantly, when focusing on how people deal with life events in different periods of their lives as a function of age, socioemotional selectivity theory (Carstensen, Isaacowitz, \& Turk-Charles, 1999) offers a theoretical framework that focuses on the individual perception of time left in life (open-ended vs. limited), and posits better emotion regulation as people get older along with fewer negative emotional experiences (Carstensen, Pasupathi, Mayr, \& Nesselroade, 2000; Gross et al., 1997). However, we were only able to find one study addressing the interplay between personality and life events in the prediction of SWB from a developmental or life span perspective. Ehrhardt and colleagues (2000) analyzed the variance of life satisfaction explained by a stable (personality) component and life changes in three different age groups. The effect of personality on life satisfaction was found to be greater for the aged than for the middle-aged or young adults and was tentatively interpreted to be due to a non-stable influence of personality on SWB throughout the life course. However, the age effects were not the pivotal point of that study and the age range of the three groups studied is not mentioned. Nevertheless, the findings suggest that with increasing age, personality traits receive greater weight in the prediction of SWB when compared to situational factors as represented by life events. This prediction is in line with the assumption of people's increasing ability throughout their lives to create and to seek environments that best fit with their personality structure (Caspi, Roberts, \& Shiner, 2005).

\subsection{The present study}

The present study has two goals: first, we examine the interplay between personality traits, subjective evaluations of reconstructed life events, and SWB using structural equation modeling. Since most of the work done so far has concentrated mainly on extraversion and neuroticism as major predictors of SWB, we also include openness, agreeableness and conscientiousness in the analyses in order to be able to control for shared variance between the personality traits and to provide a complete picture of the influence personality exerts on SWB. Second, we investigate whether the interplay is the same or different for people in different stages of their life span, more specifically, for young, middle-aged, and old adults. It is important to note, however, that we are not interested in mean-level changes of SWB in different age groups, but rather in the joint or relative contributions of personality and life events predicting SWB across age groups. Regarding life events, we focus on people's individual perception and reconstruction of consequential life events, and on their subjective evaluation of these life events with respect to the own biography.

We designed a retrospective cross-sectional study with three different age groups, each being roughly 25 years apart. Participants reported their subjective evaluation of consequential life events they had experienced throughout their lives, their current SWB, and their personality. For the total sample we expected to find a strong negative association between neuroticism $(\mathrm{N})$ and current SWB and a positive association between $\mathrm{N}$ and reconstructed negative life events. The influence of extraversion (E) on life events and SWB was assumed to be similar, but in the opposite direction: we hypothesized positive associations with SWB and positive life events. Agreeableness (A) and conscientiousness (C) were expected to be positively related to SWB, although these associations were not expected to be as strong as compared to the effects of $\mathrm{N}$ or E. For openness $(\mathrm{O})$ we expected to find positive associations with positive as well as negative life events, according to the view that open individuals tend to experience more positive as well as more negative events (Headey, 2006; Headey \& Wearing, 1989), and a weak association between O and current SWB (DeNeve \& Cooper, 1998; McCrae \& Costa, 1991). In line with previous research regarding the influence of life events on SWB (Grob, 1991, 1995; Lu, 1999; Lucas, 2005; Lucas, 2007a, 2007b; Lucas et al., 2003, 2004) we further expected a direct positive association between positive life events and SWB and a negative association between negative life events and SWB.

For the second goal, we pursued a more exploratory approach by analyzing whether the same model applies to three different age groups, namely young (approximately 25 years old), middleaged (approximately 50 years old), and old adults (approximately 75 years old). The rationale for focusing on these three age groups draws upon the positioning of these individuals in the life course and can be best described according to the concept of gains and losses throughout the life span (Heckhausen, Dixon, \& Baltes, 1989). The group of young adults is in a stage of constitution and their major task consists in finding their place in society; the life stage of the middle-aged group can be tentatively labeled as maintenance and is characterized by the fact that its members have typically already found their position in society. Finally, the major concern of old adults is to deal with decline and to accept their lived history. Thus, from a life span perspective, members of these three age groups are in different life stages and have therefore a different perspective to retrospectively evaluate their biographies. In particular, we are interested if the model holds for the three age groups or if there are differences across age groups in the way personality and life events predict SWB. According to the now wellestablished paradox that SWB mean-level does not change substantially with increasing age and that old aged individuals do not differ in their level of SWB when compared to younger people (Argyle, 1987; Staudinger, 2000), we expected young, middle-aged, and old adults not to differ in their levels of SWB, yet the way in which personality and life events predict SWB may be different across age groups. Not only do people experience less emotions with increasing age (Diener, Sandvik, \& Larsen, 1985), but they also develop better emotion regulation strategies, resulting in fewer negative emotional experiences (Carstensen et al., 1999, 2000). Based on these findings, we expected the influence of life events on SWB to be strongest for young people and to decrease with age. As for personality, we expected the influence on SWB to be stronger with increasing age (Ehrhardt et al., 2000).

Most sophistically, the effect of personality and life events on SWB across the life span would be studied in a prospective longitudinal study. The ideal study timeline would begin with a first assessment when participants are 25 years old, then a follow-up 
assessment 25 years later when they are 50 years old with an additional second sample consisting of 25 year-old participants, and finally a third assessment 25 years later with participants from the first sample being then 75 years old, participants from the second sample being 50 years old, and an additional third sample with again 25 year-old participants. However, this study would not be without its problems either: not only would societal and cultural changes along the study timeline compete with the outcome, but the scientific concepts of SWB and personality 50 years ago might differ from those used today. Finally, given the difficulties of realizing such a study as well as the tremendous financial expense it would require, we consider the cross-sectional study design to be the most adequate way in order to analyze the research question we chose.

\section{Method}

\subsection{Participants}

The sample consisted of 766 participants who lived in urban and suburban regions in German-speaking Switzerland (cities of Berne and Basel) and agreed to participate after having been sampled randomly from address lists obtained from local authorities. Participants were grouped into three age groups: young adults ( $n=256$; age range: $24-29 ; M=26.0$ years), middle-aged adults ( $n=244$; age range: $49-54 ; M=50.5$ years), and old adults ( $n=266$; age range $=74-79 ; M=75.7$ years). Sex distribution was similar across age groups (young adults: $57 \%$ women; middle-aged adults: $54 \%$ women; old adults: $45 \%$ women). Seventy percent of the old adults indicated secondary school as their highest level of education (middle-aged: 57\%, young: 34\%). The majority of participants (90\%) had lived in Switzerland since birth.

\subsection{Measures and design}

Measures were part of a larger questionnaire that included questions on consequential life events over the life span, life goals, current subjective well-being, life satisfaction over the life span, and personality and demographic measures. Results reported here concern variables measured in the sections of consequential life events, current subjective well-being and personality.

\subsubsection{Life events}

Participants were prompted with six life domains - namely education/work/occupation, family life, relationships/friendships, health/personal, leisure/culture, and political events - followed by an open category and were asked to describe up to three consequential life events they had encountered in each life domain in a free response format. They were instructed to note only the most consequential life events and to evaluate each life event according to its impact on their further life course ("How was the consequence of the particular event on your life?" positive - neutral negative). Assessment of life events was divided into four life periods: childhood to young adulthood ( $0-24$ years of age), young to middle adulthood (25-49 years of age), middle adulthood to old age (50-74 years of age), and old age to very old age (over 75 years of age). Thus, depending on their age, participants responded from different perspectives and therefore reported experienced life events in a retrospective manner or possible future life events in a prospective manner. Analyses reported here focus on retrospective life events and comprise for old adults life events they reported up to the age of 74 , for middle-aged adults life events up to the age of 49 , and for young adults life events up to the age of 24 . With this procedure we were able to approximate participants' perception of their biography along with their personal evaluation of consequential life events.
Participants mentioned a total of 10,792 retrospective life events. Of these, 8371 life events were perceived as having a positive impact, and 2421 life events as having a negative impact on the further life course. Because old adults reported life events over a longer period of time and thus mentioned more life events than younger participants, positive and negative life events were weighted by dividing the number of positive and negative life events mentioned by each person by the number of prompted life periods for each age group (old adults: number of mentioned positive and negative life events divided by three prompted life periods; middle-aged adults: number of positive and negative life events divided by two prompted life periods; young adults: number of positive and negative life events divided by one prompted life period).

\subsubsection{Subjective well-being}

SWB was measured with the scale Positive Attitude towards Life from the adult form of the Berne Questionnaire on Subjective WellBeing (BSW/A). The scale comprises following six items: (1) "My future looks good"; (2) "I enjoy life more than most people do"; (3) "Whatever happens, I can see the bright side"; (4) "I enjoy living"; (5) "My life seems meaningful to me"; (6) "My life is on track" (Grob, 1995). Evaluations were made using a six-point rating scale ranging from 1 (strongly disagree) to 6 (strongly agree) and internal consistency of these six items was $\alpha=.81$. This scale shows satisfactory convergent validity with the Satisfaction with Life Scale (Diener, Emmons, Larsen, \& Griffin, 1985) in a sample of members of three family generations (children, parents, grandparents) across four nations (Germany, Russia, Switzerland, and United States of America) and amounted to an overall correlation of .70 across nations and generations (Gomez \& Grob, in preparation).

\subsubsection{Personality}

Participants' personality was measured with an inventory based on the Big Five model of personality. The questionnaire was built according to the lexical approach (for a review see John, Angleitner, \& Ostendorf, 1988) and comprised 30 items (six items per personality facet), each item being composed of two adjectives. Example items are "fearful, nervous" for N, "sociable, talkative" for E, "creative, curious" for $\mathrm{O}$, "kind, agreeable" for A, and "thorough, dedicated" for C (for similar instruments see Gosling, Rentfrow, \& Swann, 2003; Rammstedt \& John, 2007). The majority of the adjectives used to cover the five personality facets are drawn upon Goldberg's (1992) Big Five markers. All items were ranked on a fivepoint rating scale ranging from 1 (not at all) to 5 (completely). Internal consistencies of the subscales were .66 for $\mathrm{N}, .79$ for $\mathrm{E}, .69$ for $\mathrm{O}$, .62 for $\mathrm{A}$, and .71 for $\mathrm{C}$, respectively.

\section{Results}

We analyzed relations between personality factors, positive and negative life events, and SWB in the whole sample and across age groups by means of structural equation modeling using AMOS ( $\mathrm{Ar}-$ buckle, 1997). Model comparisons and multiple-group analyses with the $\chi^{2}$ exact fit test, the root mean square error of approximation (RMSEA), and the comparative fit index (CFI) to evaluate model fit were carried out to test how the model represented the data for the whole sample and for the three age groups. RMSEA values lower than .08 and CFI values above .90 were considered as satisfactory model fit indices (Byrne, 2001). Descriptive statistics of the variables used in the models are displayed in Table 1.

\subsection{Overall model}

The structural part of the model consisted of two observed variables (positive and negative life events) and six latent variables ( $\mathrm{N}$, 
Table 1

Descriptive statistics of the variables used in the path diagram.

\begin{tabular}{|c|c|c|c|c|}
\hline & $\begin{array}{l}\text { All } \\
(N=766) \\
M(S D)\end{array}$ & $\begin{array}{l}\text { Old } \\
(n=266) \\
M(S D)\end{array}$ & $\begin{array}{l}\text { Middle-aged } \\
(n=244) \\
M(S D)\end{array}$ & $\begin{array}{l}\text { Young } \\
(n=256) \\
M(S D)\end{array}$ \\
\hline Neuroticism parcel 1 & $2.52(0.77)$ & $2.48(0.80)$ & $2.59(0.76)$ & $2.50(0.78)$ \\
\hline Neuroticism parcel 2 & $2.57(0.72)$ & $2.39(0.65)$ & $2.57(0.69)$ & $2.75(0.77)$ \\
\hline Neuroticism parcel 3 & $2.44(0.62)$ & $2.36(0.58)$ & $2.48(0.64)$ & $2.49(0.63)$ \\
\hline Extraversion parcel 1 & $3.79(0.62)$ & $3.71(0.61)$ & $3.83(0.64)$ & $3.82(0.60)$ \\
\hline Extraversion parcel 2 & $3.88(0.70)$ & $3.78(0.72)$ & $3.92(0.67)$ & $3.95(0.69)$ \\
\hline Extraversion parcel 3 & $3.79(0.74)$ & $3.79(0.71)$ & $3.85(0.75)$ & $3.75(0.75)$ \\
\hline Openness parcel 1 & $3.55(0.69)$ & $3.41(0.64)$ & $3.67(0.72)$ & $3.59(0.69)$ \\
\hline Openness parcel 2 & $3.55(0.68)$ & $3.40(0.71)$ & $3.63(0.66)$ & $3.64(0.63)$ \\
\hline Openness parcel 3 & $3.90(0.64)$ & $3.75(0.65)$ & $3.95(0.63)$ & $4.01(0.61)$ \\
\hline Agreeableness parcel 1 & $3.84(0.66)$ & $4.03(0.61)$ & $3.85(0.64)$ & $3.62(0.67)$ \\
\hline Agreeableness parcel 2 & $4.33(0.47)$ & $4.41(0.39)$ & $4.30(0.46)$ & $4.28(0.53)$ \\
\hline Agreeableness parcel 3 & $4.31(0.52)$ & $4.36(0.46)$ & $4.26(0.55)$ & $4.31(0.54)$ \\
\hline Conscientiousness parcel 1 & $3.89(0.74)$ & $4.15(0.58)$ & $3.90(0.68)$ & $3.60(0.84)$ \\
\hline Conscientiousness parcel 2 & $3.94(0.75)$ & $4.10(0.71)$ & $3.95(0.70)$ & $3.77(0.81)$ \\
\hline Conscientiousness parcel 3 & $4.29(0.56)$ & $4.36(0.50)$ & $4.36(0.52)$ & $4.15(0.64)$ \\
\hline Positive life events & $5.56(2.44)$ & $5.09(2.23)$ & $5.77(2.44)$ & $5.83(2.59)$ \\
\hline Negative life events & $1.60(1.48)$ & $1.50(1.17)$ & $1.63(1.45)$ & $1.68(1.76)$ \\
\hline SWB parcel 1 & $4.80(0.79)$ & $4.84(0.77)$ & $4.75(0.80)$ & $4.79(0.80)$ \\
\hline SWB parcel 2 & $4.82(0.73)$ & $4.75(0.73)$ & $4.79(0.70)$ & $4.91(0.73)$ \\
\hline SWB parcel 3 & $4.53(0.83)$ & $4.63(0.77)$ & $4.45(0.89)$ & $4.51(0.83)$ \\
\hline
\end{tabular}

Note: The scales measuring personality ranged from 1 to 5 , the scale measuring SWB ranged from 1 to 6 . The values for positive and negative life events are weighted values according to the number of prompted life periods for each age group.

$\mathrm{E}, \mathrm{O}, \mathrm{A}, \mathrm{C}, \mathrm{SWB})$. The indicators of the latent variables formed the measurement part of the model and were represented by aggregating items to parcels (Bandalos \& Finney, 2001; Little, Cunningham, Shahar, \& Widaman, 2002). Parcels were built according to the item-to-construct balance technique (see Little et al., 2002, p. 166). Specifically, for each latent variable, the three items with the highest item-total correlations were set as anchors of the respective parcels and the three items with the lowest values were then added to the parcels in inverted order, resulting in three parcels per latent variable in the model. The structural model was con- structed on established research findings with personality factors $(\mathrm{N}, \mathrm{E}, \mathrm{O}, \mathrm{A}, \mathrm{C})$ and positive and negative life events as predictors of SWB. Each personality trait, positive life events, and negative life events were expected to be direct predictors of SWB. That is, the level of $\mathrm{N}$ for instance, the occurrence of positive life events, and the occurrence of negative life events co-determine a person's SWB. Furthermore, personality influenced the experience of positive as well as negative life events. Covariances were assumed between each latent personality factor in order to control for shared variance between the personality traits as well as between the error terms of positive and negative life events, as evidence suggests the two types of life events to be substantially related to one another (e.g., Block \& Zautra, 1981). Fig. 1 displays the overall model with the standardized estimates. The intercorrelations between the latent personality facets are not represented graphically as this may render the figure unclear, and are therefore provided in Table 2 . Some of the Big Five factors are substantially correlated with each other (e.g., correlations up to .66 between $\mathrm{E}$ and $\mathrm{O}$ in the total sample). Although these correlations contradict the often-claimed orthogonality of the five personality dimensions (e.g., Goldberg, 1992), they are in line with empirical findings reporting important correlations between the personality domains (see Block, 1995 for a comprehensive elaboration).

Table 2

Internal consistencies and intercorrelations among the personality dimensions in the overall model $(N=766)$.

\begin{tabular}{llllll}
\hline & $\mathrm{N}$ & $\mathrm{E}$ & $\mathrm{O}$ & $\mathrm{A}$ & $\mathrm{C}$ \\
\hline 1. Neuroticism & $(.66)$ & & & & \\
2. Extraversion & $-.57^{* * *}$ & $(.79)$ & & & \\
3. Openness & $-.55^{* * *}$ & $.66^{* * *}$ & $(.69)$ & & \\
4. Agreeableness & $-.12^{*}$ & $.25^{* * *}$ & -.08 & $(.62)$ & \\
5. Conscientiousness & $-.18^{* * *}$ & .07 & $-.10^{*}$ & $.62^{* * *}$ & $(.71)$
\end{tabular}

Note: Correlations are reported below the diagonal. Internal consistency of the scales (Cronbach's alpha) is reported in parentheses along the diagonal. $\mathrm{N}=\mathrm{Neu}-$ roticism; $\mathrm{E}=$ Extraversion $; \mathrm{O}=$ Openness; $\mathrm{A}=$ Agreeableness $; \mathrm{C}=$ Conscientiousness . * $p<.05$.

$p<.001$.

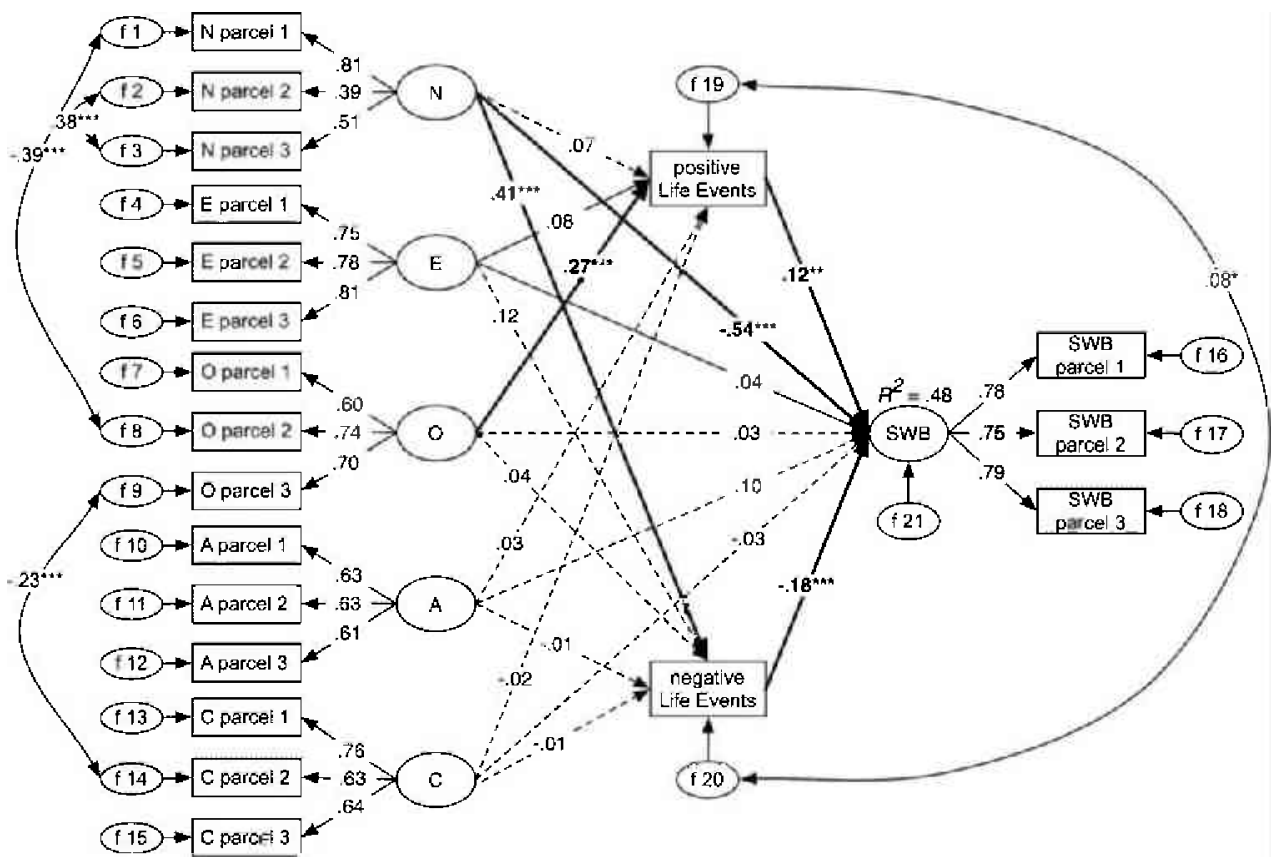

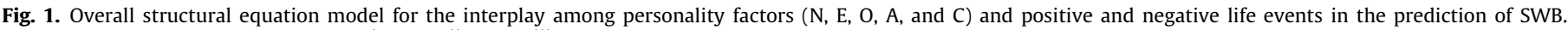
Standardized coefficients are displayed. ${ }^{*} p<.05 ;{ }^{* *} p<.01 ;{ }^{* * *} p<.001$ 


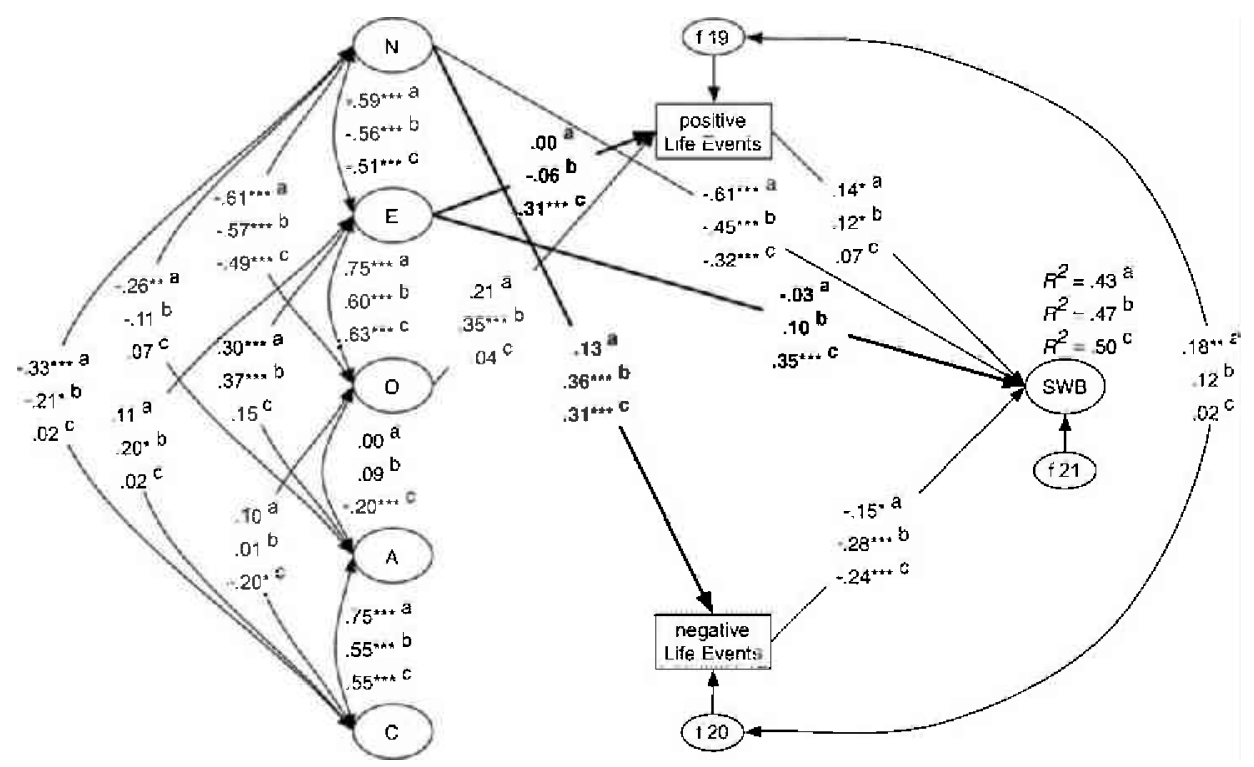

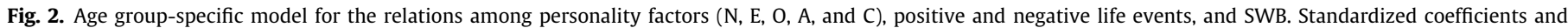
correlations of the free estimated model are reported for each age group separately ( ${ }^{\mathrm{a}}$ old adults; ${ }^{\mathrm{b}}$ middle-aged adults; ${ }^{\mathrm{c}} \mathrm{young}$ adults). ${ }^{*} p<.05 ;{ }^{* *} p<.01 ;{ }^{* * *} p<.001$.

For the overall sample, $\mathrm{N}$ turned out to be the strongest and unique personality-related predictor of SWB in the model $(\beta=-.54, p<.001)$, followed by negative life events $(\beta=-.18$, $p<.001)$, and positive life events $(\beta=.12, p<.01)$. Negative life events were predicted by $\mathrm{N}(\beta=.41, p<.001)$, whereas positive life events were predicted by $\mathrm{O}(\beta=.27, p<.001)$. The correlation between the error terms of positive and negative life events was significant $(r=.08 ; p<.05)$. When regarding the non-significant path coefficients, $\mathrm{N}$ and $\mathrm{E}$ were not directly related to positive life events ( $\beta=.07, p=.26$, and $\beta=.08, p=.29$, respectively). Furthermore, $\mathrm{E}$ and $\mathrm{O}$ were not related to negative life events ( $\beta=.12, p=.15$, and $\beta=.04, p=.56$, respectively), and both of them also failed to significantly predict SWB $(\beta=.04, p=.60$ for $\mathrm{E}$, and $\beta=.03, p=.65$ for $\mathrm{O}$, respectively). The paths from the personality factors of $A$ and $C$ did not reach significance, neither for the occurrence of positive life events $(\beta=.03, p=.74$, and $\beta=-.02, \quad p=.74$, respectively), nor for negative life events ( $\beta=-.01, p=.86$, and $\beta=-.01, p=.87$, respectively), nor for actual SWB $(\beta=.10, p=.16$, and $\beta=-.03, p=.64$, respectively). Based on the suggested modification indices, three additional covariances were added to the measurement model between the error terms of the personality indicator variables (see Fig. 1). These model specifications resulted in a good representation of the data: $\chi^{2}(141)=492.28(p<.001) ; \quad \operatorname{RMSEA}=.057$, $\mathrm{CFI}=.926$, and accounted for $48 \%$ of the variance in SWB. Note that the chi-square statistic is highly sensitive to big sample sizes, whereas RMSEA and CFI values are more appropriate to evaluate model fit. In order to simplify the model, each of the aforementioned non-significant path coefficients were restricted to zero (dashed paths in Fig. 1) with the exception of the two paths from E to SWB and from E to positive life events. These exceptions were justified by empirical evidence for the influence of E on SWB (Chico-Libran, 2006; Headey \& Wearing, 1992; Lucas \& Fujita, 2000; Pavot et al., 1990; Vittersø \& Nilsen, 2002; Watson \& Clark, 1992), and on positive life events (Headey \& Wearing, 1989; Magnus et al., 1993). Because these model simplifications did not result in a deterioration of the model fit, $\Delta \chi^{2}$ $(10)=12.20(p=.27)$, and the fit indices turned out to be as good as in the overall model (RMSEA $=.055, \mathrm{CFI}=.925$ ) further analyses and age group comparisons were carried out using the simplified model.

\subsection{Age group comparisons}

SWB was first analyzed using a three (age group) by two (sex) between-subjects ANOVA, revealing no significant differences in SWB scores across age or gender, $F(2760)=0.96, p=.38$, and $F(1760)=0.88, p=.35$, respectively. We further applied multiplegroup comparisons using the $\chi^{2}$ exact fit test between the models with free and invariant path coefficients to test whether the same model structure would fit for the young, middle-aged and old age group. In a first step, the simplified model was applied to each age group separately with no constraint on the path coefficients. Then, we set the model under constraint by assuming the paths to be invariant, i.e. equal across age groups. If the relations between personality, life events, and SWB are the same across ages, a constrained invariant three-group model should show the same fit parameters as a free estimated model.

Fig. 2 shows the structural part of the model with free estimated path coefficients for young, middle-aged, and old adults, revealing a good representation of the data, $\chi^{2}(453)=823.75$ $(p<.001)$, RMSEA $=.033, \mathrm{CFI}=.921$, and explaining $43 \%, 47 \%$, and $50 \%$ of the variance in SWB for old, middle-aged, and young adults, respectively. Fit statistics and model comparisons emerging from multiple-group analyses are displayed in Table 3. First (step 1), all the paths in the model were set invariant across age groups: the paths from $\mathrm{N}$ and $\mathrm{E}$ to $\mathrm{SWB}$, the paths from positive and negative life events to SWB, the paths from $\mathrm{E}$ and $\mathrm{O}$ to positive life events, and the path from $\mathrm{N}$ to negative life events. Analysis of the $\chi^{2}$ difference between the two models revealed a significant deterioration of the model fit, $\Delta \chi^{2}(14)=35.21(p<.01)$, indicating that the relations are not the same across age groups.

Next, in order to identify the paths that led to the deterioration of the model fit, each parameter in the model was set invariant one after the other (always one parameter was constrained to be equal across groups, whereas the remaining six paths were freely estimated). Significant $\chi^{2}$ differences between the model with free and constrained estimates emerged when setting the paths from E to SWB (step 2), from E to positive life events (step 3), and from $\mathrm{N}$ to negative life events (step 4) invariant (bold paths in Fig. 2). $\mathrm{E}$ significantly predicted SWB only in the youngest age group $(\beta=.35, p<.001)$, whereas no significant effect emerged for old $(\beta=-.03, p=.78)$, and middle-aged adults $(\beta=.10, p=.24)$. Consis- 
Table 3

Summary of fit statistics for multiple-group analyses.

\begin{tabular}{|c|c|c|c|c|c|}
\hline Type of analysis & $\chi^{2}$ & $\mathrm{df}$ & CFI & RMSEA & $\Delta \chi^{2}(\Delta \mathrm{df})$ \\
\hline Free estimated model & 823.75 & 453 & .921 & .033 & \\
\hline Step 1: invariant path coefficients & 858.96 & 467 & .917 & .033 & \\
\hline Difference between Step 1 and free estimated model & & & & & $35.21^{* *}(14)$ \\
\hline Step 2: E to SWB invariant & 831.53 & 455 & .920 & .033 & \\
\hline Difference between Step 2 and free estimated model & & & & & $7.78^{*}(2)$ \\
\hline Step 3: E to positive life events invariant & 832.50 & 455 & .920 & .033 & \\
\hline Difference between Step 3 and free estimated model & & & & & $8.75^{*}(2)$ \\
\hline Step 4: $\mathrm{N}$ to negative life events invariant & 832.11 & 455 & .920 & .033 & \\
\hline Difference between Step 4 and free estimated model & & & & & $8.36^{*}(2)$ \\
\hline Step 5: $\mathrm{N}$ to SWB invariant & 826.34 & 455 & .921 & .033 & \\
\hline Difference between Step 5 and free estimated model & & & & & $2.59(2)$ \\
\hline Step 6: negative life events to SWB invariant & 824.89 & 455 & .921 & .033 & \\
\hline Difference between Step 6 and free estimated model & & & & & $1.14(2)$ \\
\hline Step 7: positive life events to SWB invariant & 824.69 & 455 & .921 & .033 & \\
\hline Difference between Step 7 and free estimated model & & & & & $0.94(2)$ \\
\hline Step 8: O to positive life events invariant & 827.06 & 455 & .921 & .033 & \\
\hline Difference between Step 8 and free estimated model & & & & & $3.31(2)$ \\
\hline
\end{tabular}

Note : CFI = comparative fit index; RMSEA = root mean square error of approximation. $\mathrm{N}=$ Neuroticism; $\mathrm{E}=\mathrm{Extraversion} ; \mathrm{O}=\mathrm{Openness}$; $\mathrm{SWB}=\mathrm{Subjective}$ well-being. $p<.05$.

$p<.01$.

tently, a significant deterioration of the model fit emerged when setting the path from E to SWB invariant across groups, $\Delta \chi^{2}$ $(2)=7.78(p<.05)$ (Table 3 , step 2$)$. Similarly, it was only in young adults that $\mathrm{E}$ significantly influenced positive life events $(\beta=.31$, $p<.001)$, and no effects emerged in middle-aged $(\beta=-.06$, $p=.50)$ and old adults $(\beta=.00, p=.97)$. Results from model comparisons further confirmed the inequality of this path across groups (step 3), $\Delta \chi^{2}(2)=8.75(p<.05)$. Finally, the path from $\mathrm{N}$ to negative life events (step 4$)$ turned out to operate differently across age groups, $\Delta \chi^{2}(2)=8.36(p<.05)$, as $\mathrm{N}$ was directly related to negative life events only in middle-aged $(\beta=.36, p<.001)$ and young adults $(\beta=.31, p<.001)$, whereas it marginally failed to reach significance in old adults $(\beta=.13, p=.06)$ (Fig. 2$)$.

When successively setting the paths from $\mathrm{N}$ to SWB (step 5 ), from negative life events to SWB (step 6), from positive life events to SWB (step 7), and from $O$ to positive life events (step 8) invariant across groups, no significant deteriorations of model fit emerged for either of the model comparisons. In detail, when analyzing the path from N to SWB (step 5), results from model comparisons suggested this path to be invariant across age groups, $\Delta \chi^{2}$ $(2)=2.59(p=.28)$, despite a decreasing effect from the oldest to the youngest participants $(\beta=-.61, p<.001$ for old adults, $\beta=-.45, p<.001$ for middle-aged adults, and $\beta=-.32, p<.001$ for young adults, respectively). Similarly, negative life events seemed to be more strongly related to SWB for middle-aged $(\beta=-.28, p<.001)$ and young adults $(\beta=-.24, p<.001)$ as compared to old adults $(\beta=-.15, p<.01)$, but when restraining this path to be equal across age groups (step 6), the $\chi^{2}$ difference between the free estimated and the restrained model was not significant, $\Delta \chi^{2}(2)=1.14(p=.57)$, and pointed to an equal influence of negative life events across ages. The influence of positive life events on SWB (step 7) also proved to be invariant across age groups, $\Delta \chi^{2}(2)=0.94(p=.63)$, although the path was significant only in old $(\beta=.14, p<.05)$ and middle-aged adults $(\beta=.12$, $p<.05)$, but not so in young adults $(\beta=.07, p=.22)$. And finally, although $\mathrm{O}$ significantly predicted positive life events (step 8 ) only in middle-aged adults $(\beta=.35, p<.001)$, but not in old and young adults $(\beta=.21, p=.11$, and $\beta=.04, p=.68$, respectively), model comparisons revealed this path to be invariant across age groups, $\Delta \chi^{2}(2)=3.31(p=.19)$.

Subsequent analyses were conducted according to a procedure suggested by Kunzmann, Little, and Smith (2000) in order to test if the strength of two paths significantly differed from one another. Beyond results from multiple-group comparisons, these path com- parisons allow a more thorough representation of the distinct influences across age groups by clearly determining whether there is a significant difference in the strength of the path estimates to be analyzed. ${ }^{1}$ Therefore, for each age group, each path was compared with the respective path of the other two groups. Results from these additional analyses will only be reported for those paths that were invariant according to multiple-group comparisons (paths from $\mathrm{N}$ to $S W B$, from negative and positive life events to $S W B$, and from $O$ to positive life events). The effect of $\mathrm{N}$ on SWB was significantly stronger for old as compared to young adults $(\Delta z=-2.51, p<.05)$, and a trend towards significance was obtained when compared to middle-aged adults $(\Delta z=-1.32, p=.09)$, whereas the path was shown to be invariant for the two younger age groups $(\Delta z=-1.8$, $p=.12$ ). Concerning the path from negative life events to SWB, results yielded a significant difference between old and middle-aged adults $(\Delta z=1.97, p<.05)$, a trend towards significance between old and young adults $(\Delta z=1.31, p=.09)$, and finally no significant difference between middle-aged and young adults $(\Delta z=-0.70$, $p=.24$ ), suggesting a stronger effect of negative life events on SWB for the two younger age groups. In contrast, additional comparisons of the influence of positive life events on SWB yielded no significant differences and supported the assumption of an equal influence of positive life events on SWB across age groups $(\Delta z=0.36, p=.36$ for the comparison old - middle-aged adults; $\Delta z=1.17, p=.12$ for the comparison old - young adults; $\Delta z=0.81, p=.21$ for the comparison middle-aged - young adults). Finally, 0 predicted positive life events more strongly in middle-aged participants as compared to young adults $(\Delta z=3.08, p<.05)$, a trend towards a stronger influence was obtained when comparing old and young adults $(\Delta z=1.49, p=.07)$, whereas the path was invariant for old and middle-aged adults $(\Delta z=1.18, p=.12)$.

In addition, the correlation between the error terms of positive and negative life events turned out to be significant only for old adults $(r=.18, p<.01)$, but not for middle-aged $(r=.12, p=.07)$ and young adults $(r=.02, p=.81)^{2}$

\footnotetext{
1 Computation of the test statistic $(\Delta z)$ was based on following formula:

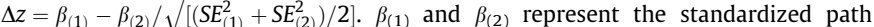
coefficient of the paths to be compared, and $\mathrm{SE}_{(1)}$ and $\mathrm{SE}_{(2)}$ are the standardized standard errors (approximated by taking the standardized path coefficient and dividing it by the $z$-value from the unstandardized solution). In cases where the test statistic $(\Delta z)$ exceeds \pm 1.65 , the two paths differ significantly ( $p<\theta .05$, one-tailed) from one another.

2 Analyses were also conducted with unweighted scores for positive and negative life events and yielded identical results.
} 


\section{Discussion}

This study had two goals. First, to analyze how personality factors and experienced positive and negative life events influence $\mathrm{SWB}$, and second to investigate differences across people in different life stages by testing the same model for young, middle-aged, and old adults. Therefore, participants' personality and their subjective evaluation of reconstructed life events were assessed and related to their current SWB.

The postulated relations between personality, life events and SWB for the total sample were partially supported. The strongest predictive effect on SWB was found for N, followed by negative and positive life events. Moreover, $\mathrm{N}$ predicted negative life events, whereas $\mathrm{O}$ was significantly related to positive life events. However, some of the expected effects were not confirmed: E, O, A, and $C$ failed to show significant effects on SWB, E turned out to be unrelated to positive life events, and the same was true for $O$ and negative life events. Thus, our data did not fully support existing findings suggesting substantial correlations between N, E, A, C and SWB and a weaker but significant association between $\mathrm{O}$ and SWB (DeNeve \& Cooper, 1998; McCrae \& Costa, 1991; Steel et al., 2008): While N clearly predicted SWB, the other personality factors did not. As hypothesized, reconstructed life events significantly influenced SWB with a stronger effect for negative as compared to positive life events. Although these results clearly indicate a substantial influence of life events on SWB, we cannot conclude whether this influence is due to recent life events or if there is also a long-lasting influence of life events on SWB. Subsequent analyses are needed in order to clarify if life events that occurred several years ago predict SWB equally well as more recent ones. Against our predictions and in contrast to previous findings (Headey, 2006; Headey \& Wearing, 1989), O was positively related only to positive life events and not to negative ones. This might be due to the different underlying elements of O like intellectual, cultural, creativity, and cognitive components (DeNeve \& Cooper, 1998; John, 1990). In our study, one could argue that these intellectual components might foster a positive interpretation of negative events as a result of healthy coping strategies, leading open individuals to experience and remember more positive events and to disregard more negative ones. Furthermore, $\mathrm{N}$ was positively related to negative life events, whereas $\mathrm{E}$ failed to predict positive life events in the total sample. Because of empirical evidence suggesting a substantial influence of E not only on SWB (Chico-Libran, 2006; Headey \& Wearing, 1992; Lucas \& Fujita, 2000; Pavot et al., 1990; Vittersø \& Nilsen, 2002; Watson \& Clark, 1992), but also on positive life events (Headey \& Wearing, 1989; Magnus et al., 1993) we analyzed these assumed relations in the model while testing differences across age groups.

As for the second goal, the analysis of differences in the way personality and life events predict SWB across the life span as a function of age, results from multiple-group comparisons revealed the paths from $E$ to SWB, the path from E to positive life events, and the path from $\mathrm{N}$ to negative life events to differ between young, middle-aged, and old adults, whereas the influence of N on SWB, of negative and positive life events on SWB, and of $O$ on positive life events was invariant according to multiple-group comparisons. However, additional analyses of the strength of the parameter estimates across groups did indeed point to age-related differences in paths that had previously been suggested to be invariant across ages: against previous results claiming for a stronger influence of personality on SWB in old people (Ehrhardt et al., 2000), we found the opposite to be true as far as $\mathrm{E}$ is concerned. Although no significant influence of E on SWB emerged for the total sample, a clear age effect was found, with a substantial influence of $E$ on SWB in young adults but none in middle-aged and old adults. In contrast, we found the effect of $\mathrm{N}$ on SWB to be stronger for old adults as compared to middle-aged and young adults. Therefore, with increasing age, $\mathrm{N}$ becomes the dominant personality-related predictor for SWB, whereas the influence of E on SWB is only existent in young adults and disappears with increasing age.

One hypothesis received only partial support. Evidence for a stronger influence of life events on SWB in young people was only found for negative, but not for positive life events. Although positive life events were significantly related to SWB exclusively in old and middle-aged adults, both multiple-group comparisons and additional path comparisons revealed the influence of positive life events on SWB to be equal across age groups. As for negative life events, additional analyses of the standardized estimates supported our prediction and showed the path to be stronger for middle-aged and young adults as compared to old participants (trend to significance for the comparison old adults, young adults). These findings are consistent with previous evidence stating that people experience less emotions related to their experiences with increasing age (Diener et al., 1985). Our data further suggest that old people do not necessarily experience less consequential life events. But obviously, and despite the higher likeliness to experience negative life events with increasing age, the influence of negative events on SWB is not as strong in old people as compared to their younger counterparts and implies that old people find ways to successfully cope with adverse events. In accordance with the concept of successful aging derived from the model of selection, optimization, and compensation (Baltes \& Baltes, 1990; see also Baltes, 1997), and socioemotional selectivity theory (Carstensen et al., 1999, 2000), old people seem to be better able not only to regulate emotions or to compensate age-related losses, but negative life events in general and, in doing so, buffer the resulting negative effect on SWB. When considering Erikson's stage theory of psychosocial development (Erikson, 1980), successful mastery of the last psychosocial crisis (integrity vs. despair) leads to a sense of fulfillment and to wisdom. This occurs when people manage to look back on positive life events with gladness and are not only able to accept negative life events, but also to integrate them as part of their selves. Obviously, life reflection and self-insight (Staudinger, 2001) can contribute to find meaning in losses and negative life events and might result in maturation and development or - in Erikson's terms - wisdom.

Differences across age groups in the way positive life events are predicted by personality factors emerged for $\mathrm{E}$ and $\mathrm{O}$ : whereas $\mathrm{E}$ predicted positive life events only in young adults, the influence of $\mathrm{O}$ on positive life events was stronger in middle-aged adults. Negative life events, however, were more strongly predicted by $\mathrm{N}$ in the two younger age groups. Moreover, a significant correlation between the error terms of positive and negative life events emerged only in the oldest age group and indicated that old adults who experienced many events of one kind were more likely to experience many events of the other kind. But interestingly, life events were not related to each other in middle-aged and young adults. This finding is surprising, insofar as the correlation between positive and negative life events has already been described elsewhere (e.g., Block \& Zautra, 1981) and has therefore been taken for granted to emerge for each age group. However, our results reveal differences across the life span and suggest reconstructed positive and negative life events to be only related to one another with increasing age.

Two main shortcomings of the study should be considered when interpreting these findings. First, because of the cross-sectional study design, age and cohort effects are confounded, thus requiring a cautious interpretation of differences between the age groups. Only a longitudinal study would allow us to distinguish 
between age and cohort effects. Similarly, in order to analyze adaptation to life events, longitudinal studies are needed in which baseline levels of SWB and personality are assessed and evaluation of life events and SWB are recorded throughout the study timeline. However, as already mentioned, in order to properly investigate the described relations within a longitudinal study with a timeline of 50 years would not only imply a major scientific and financial challenge, but would also have to face problems due to societal changes and changes in scientific understanding of the concepts under study. Moreover, a comprehensive picture of the correlates of SWB should measure all its components, including positive affect, negative affect and life satisfaction. Only by doing so is consideration given to the fact that SWB is not a unitary concept, but one consisting of both emotional and cognitive components (Diener et al., 1999; Lucas et al., 1996). The second limitation concerns the use of open format questions to retrospectively assess experienced life events and the subsequent subjective evaluation concerning the perceived positive or negative impact on the further life course. Although participants were instructed to note only the most consequential life events they had experienced throughout their lives, it still remains a matter of individual interpretation - or even personality - which life events are appraised as consequential for the self and whether these events are perceived as positive or negative for the further life course. However, because participants were prompted with different life domains, assessment of reconstructed life events can be viewed as something akin to a cued recall, thus minimizing the room for participants to freely recall life events that are only currently active in their memory due to their prevailing mood state. Alternatively, assessment of life events could have been carried out with a life events checklist with participants facing a list of given positive and negative events and deciding for each event if they had experienced it or not (e.g., Suh et al., 1996). However, we were not interested in an assessment of objective positive or negative life events, but rather in a subjective reconstruction and subsequent personal evaluation of life events. Moreover, given the characteristics of our sample with participants from three age groups each 25 years apart, it seems difficult to establish an inventory with life events that are applicable to young, middle-aged, and old adults.

This study responded to the repeated claim that research on SWB should not only focus on stable and dispositional factors (top-down approach), but also include situational factors (bottom-up approach) in order to fully understand the causes and mechanisms of SWB. Moreover, we tried to extend findings by Ehrhardt et al. (2000) to explore possible differences in the joint contribution of personality and life events on SWB across the life span. To our knowledge, the integration of all Big Five factors in an overall model is the first attempt so far to provide a complete picture of the interplay between personality, life events, and SWB and to further analyze the resulting model across different age groups.

To sum up, our results implicate $\mathrm{N}$ and positive and negative life events as direct predictors of SWB in the overall sample. The strength of the influence of $\mathrm{N}$ and negative life events on SWB differs across ages. Additionally, E is directly related to SWB only in young adults. Future research should rely on longitudinal studies to more accurately examine interactions between personality and long-term effects of life events on SWB, and to differentially investigate these effects across ages and cohorts.

\section{Acknowledgments}

This study was supported by a Grant (No. 5004-47766) from the Swiss National Science Foundation awarded to Alexander Grob in the context of the Swiss Priority Program "Switzerland - Towards the Future."

\section{References}

Abbey, A., \& Andrews, F. M. (1985). Modeling the psychological determinants of life quality. Social Indicators Research, 16, 1-34.

Arbuckle, J. (1997). Amos user's guide: Version 3.6. Chicago: Small Waters.

Argyle, M. (1987). The psychology of happiness. New York: Methuen.

Baltes, P. B. (1997). On the incomplete architecture of human ontogeny: Selection, optimization, and compensation as foundation of developmental theory. American Psychologist, 52, 366-380.

Baltes, P. B., \& Baltes, M. M. (1990). Psychological perspectives on successful aging: The model of selective optimization with compensation. In P. B. Baltes \& M. M. Baltes (Eds.), Successful aging: Perspectives from the behavioral sciences (pp. 1-34). New York: Cambridge University Press.

Bandalos, D. L., \& Finney, S. J. (2001). Item parceling issues in structural equation modeling. In G. A. Marcoulides \& R. E. Schumacker (Eds.), New developments and techniques in structural equation modeling (pp. 269-296). Mahwah, NJ: Lawrence Erlbaum.

Block, J. (1995). A contrarian view of the five-factor approach to personality description. Psychological Bulletin, 117, 187-215.

Block, M., \& Zautra, A. (1981). Satisfaction and distress in a community: A test of the effects of life events. American Journal of Community Psychology, 9, 165-180.

Brickman, P., \& Campbell, D. T. (1971). Hedonic relativism and planning the good society. In M. H. Appley (Ed.), Adaptation-level theory (pp. 287-305). New York: Academic Press.

Brickman, P., Coates, D., \& Janoff-Bulman, R. (1978). Lottery winners and accident victims: Is happiness relative? Journal of Personality and Social Psychology, 36, 917-927.

Byrne, B. M. (2001). Structural equation modeling with AMOS: Basic concepts, applications, and programming. Mahwah, NJ: Lawrence Erlbaum.

Campbell, A., Converse, P. E., \& Rodgers, W. L. (1976). The quality of American life. New York: Russell Sage.

Carstensen, L. L., Isaacowitz, D. M., \& Turk-Charles, S. (1999). Taking time seriously: A theory of socioemotional selectivity. American Psychologist, 54, 165-181.

Carstensen, L. L., Pasupathi, M., Mayr, U., \& Nesselroade, J. R. (2000). Emotional experience in everyday life across the adult life span. Journal of Personality and Social Psychology, 79, 644-655.

Caspi, A., Roberts, B. W., \& Shiner, R. L. (2005). Personality development: Stability and change. Annual Review of Psychology, 56, 453-484.

Chico-Libran, E. (2006). Personality dimensions and subjective well-being. Spanish Journal of Psychology, 9, 38-44.

Costa, P. T., Jr., Herbst, J. H., McCrae, R. R., \& Siegler, I. C. (2000). Personality at midlife: Stability, intrinsic maturation, and response to life events. Assessment, 7, 365-378.

Costa, P. T., Jr., \& McCrae, R. R. (1980). Influence of extraversion and neuroticism on subjective well-being: Happy and unhappy people. Journal of Personality and Social Psychology, 38, 668-678.

Costa, P. T., Jr., \& McCrae, R. R. (1984). Personality as a lifelong determinant of wellbeing. In C. Malatesta \& C. Izard (Eds.), Affective processes in adult development and aging (pp. 141-156). Beverly Hills, CA: Sage.

Costa, P. T., \& McCrae, R. R. (1997). Longitudinal stability of adult personality. In R. Hogan, J. Johnson, \& S. Briggs (Eds.), Handbook of personality psychology (pp. 269-292). San Diego: Academic Press.

DeNeve, K. M., \& Cooper, H. (1998). The happy personality: A meta-analysis of 137 personality traits and subjective well-being. Psychological Bulletin, 124, $197-229$.

Diener, E. (1984). Subjective well-being. Psychological Bulletin, 95, 542-575.

Diener, E., Emmons, R. A., Larsen, R. J., \& Griffin, S. (1985). The Satisfaction with life scale. Journal of Personality Assessment, 49, 71-75.

Diener, E., \& Larsen, R. J. (1993). The experience of emotional well-being. In M. Lewis \& J. M. Haviland (Eds.), Handbook of emotions (pp. 404-415). New York: Guilford Press.

Diener, E., \& Lucas, R. E. (1999). Personality and subjective well-being. In D. Kahnemann, E. Diener, \& N. Schwarz (Eds.), The foundations of hedonic psychology (pp. 213-229). New York: Russell Sage.

Diener, E., Lucas, R. E., \& Scollon, C. N. (2006). Beyond the hedonic treadmill: Revising the adaptation theory of well-being. American Psychologist, 61, 305-314.

Diener, E., Sandvik, E., \& Larsen, R. J. (1985). Age and sex effects for emotional intensity. Developmental Psychology, 21, 542-546.

Diener, E., Suh, E. M., Lucas, R. E., \& Smith, H. L. (1999). Subjective well-being: Three decades of progress. Psychological Bulletin, 125, 276-302.

Ehrhardt, J. J., Saris, W. E., \& Veenhoven, R. (2000). Stability of life-satisfaction over time: Analysis of change in ranks in a national population. Journal of Happiness Studies, 1, 177-205.

Erikson, E. H. (1980). Identity and the life cycle. New York: W.W. Norton \& Company, Inc.

Goldberg, L. R. (1992). The development of markers for the big-five factor structure. Psychological Assessment, 4, 26-42.

Gomez, V., \& Grob, A. (in preparation). Personality and life goals across family generations and nations: How are they related to subjective well-being?-

Gosling, S. D., Rentfrow, P. J., \& Swann, W. B. Jr., (2003). A very brief measure of the big-five personality domains. Journal of Research in Personality, 37, 504-528.

Grob, A. (1991). Der Einfluss bedeutsamer Lebensereignisse auf das Wohlbefinden und die bereichsspezifischen Kontrollmeinungen von Jugendlichen [The influence of significant life events on subjective well-being and domain- 
specific control attributions of adolescents]. Swiss Journal of Psychology, 50, 48-63.

Grob, A. (1995). Subjective well-being and significant life-events across the life span. Swiss Journal of Psychology, 54, 3-18.

Grob, A., Krings, F., \& Bangerter, A. (2001). Life markers in biographical narratives of people from three cohorts: A life span perspective in its historical context. Human Development, 44, 171-190.

Gross, J. J., Carstensen, L. L., Pasupathi, M., Tsai, J., Skorpen, C. G., \& Hsu, A. Y. C. (1997). Emotion and aging: Experience, expression, and control. Psychology and Aging, 12, 590-599.

Havighurst, R. J. (1948). Developmental tasks and education. New York: David McKay.

Headey, B. (2006). Subjective well-being: Revisions to dynamic equilibrium theory using national panel data and panel regression methods. Social Indicators Research, 79, 369-403.

Headey, B. (2008). The set point theory of well-being: Negative results and consequent revisions. Social Indicators Research, 85, 389-403.

Headey, B., Glowacki, T., Holmstrom, E. L., \& Wearing, A. J. (1985). Modelling change in perceived quality of life. Social Indicators Research, 17, 276-298.

Headey, B., Holmstrom, E. L., \& Wearing, A. J. (1984). The impact of life events and changes in domain satisfactions on well-being. Social Indicators Research, 15, 203-227.

Headey, B., \& Wearing, A. (1989). Personality, life events, and subjective well-being: Toward a dynamic equilibrium model. Journal of Personality and Social Psychology, 57, 731-739.

Headey, B., \& Wearing, A. J. (1992). Understanding happiness: A theory of subjective well-being. Melbourne: Longman Cheshire.

Heckhausen, J., Dixon, R. A., \& Baltes, P. B. (1989). Gains and losses in development throughout adulthood as perceived by different adult age groups. Developmental Psychology, 25, 109-121.

Helson, R., Jones, C., \& Kwan, V. S. Y. (2002). Personality change over 40 years of adulthood: Hierarchical linear modeling analyses of two longitudinal samples. Journal of Personality and Social Psychology, 83, 752-766.

John, O. P. (1990). The "Big Five" factor taxonomy: Dimensions of personality in the natural language and in questionnaires. In L. A. Pervin (Ed.), Handbook of personality: Theory and research (pp. 66-100). New York: Guilford Press.

John, O. P., Angleitner, A., \& Ostendorf, F. (1988). The lexical approach to personality: A historical review of trait taxonomic research. European Journal of Personality, 2, 171-203.

Kunzmann, U., Little, T. D., \& Smith, J. (2000). Is age-related stability of subjective well-being a paradox? Cross-sectional and longitudinal evidence from the Berlin aging study. Psychology and Aging, 15, 511-526.

Little, T. D., Cunningham, W. A., Shahar, G., \& Widaman, K. F. (2002). To parcel or not to parcel: Exploring the question, weighing the merits. Structural Equation Modeling, 9, 151-173.

Lu, L. (1999). Personal or environmental causes of happiness: A longitudinal analysis. Journal of Social Psychology, 139, 79-90.

Lucas, R. E. (2005). Time does not heal all wounds: A longitudinal study of reaction and adaptation to divorce. Psychological Science, 16, 945-950.

Lucas, R. E. (2007a). Long-term disability is associated with lasting changes in subjective well-being: Evidence from two nationally representative longitudinal studies. Journal of Personality and Social Psychology, 92, 717-730.

Lucas, R. E. (2007b). Adaptation and the set-point model of subjective well-being: Does happiness change after major life events? Current Directions in Psychological Science, 16, 75-79.

Lucas, R. E., Clark, A. E., Georgellis, Y., \& Diener, E. (2003). Reexamining adaptation and the set point model of happiness: Reactions to changes in marital status. Journal of Personality and Social Psychology, 84, 527-539.

Lucas, R. E., Clark, A. E., Georgellis, Y., \& Diener, E. (2004). Unemployment alters the set point for life satisfaction. Psychological Science, 15, 8-13.
Lucas, R. E., Diener, E., \& Suh, E. (1996). Discriminant validity of well-being measures. Journal of Personality and Social Psychology, 71, 616-628.

Lucas, R. E., \& Donnellan, M. B. (2007). How stable is happiness? Using the STARTS model to estimate the stability of life satisfaction. Journal of Research in Personality, 41, 1091-1098.

Lucas, R. E., \& Fujita, F. (2000). Factors influencing the relation between extraversion and pleasant affect. Journal of Personality and Social Psychology, 79, 1039-1056.

Lykken, D., \& Tellegen, A. (1996). Happiness is a stochastic phenomenon. Psychological Science, 7, 186-189.

Lyubomirsky, S., Sheldon, K. M., \& Schkade, D. (2005). Pursuing happiness: The architecture of sustainable change. Review of General Psychology, 9, 111-131.

Magnus, K., Diener, E., Fujita, F., \& Pavot, W. (1993). Extraversion and neuroticism as predictors of objective life events: A longitudinal analysis. Journal of Personality and Social Psychology, 65, 1046-1053.

McCrae, R. R., \& Costa, P. T. (1991). Adding Liebe and Arbeit: The full five-factor model and well-being. Personality and Social Psychology Bulletin, 17, 227-232.

McCrae, R. R., Costa, P. T., Jr., Ostendorf, F., Angleitner, A., Hřebíčková, M., Avia, M. D. et al. (2000). Nature over nurture: Temperament, personality, and life span development. Journal of Personality and Social Psychology, 78, 173-186.

Myers, D. G. (1992). The pursuit of happiness: Who is happy and why. New York: William Morrow.

Myers, D. G., \& Diener, E. (1995). Who is happy? Psychological Science, 6, 10-19.

Nes, R. B., Røysamb, E., Tambs, K., Harris, J. R., \& Reichborn-Kjennerud, T. (2006) Subjective well-being: Genetic and environmental contributions to stability and change. Psychological Medicine, 36, 1033-1042.

Pavot, W., Diener, E., \& Fujita, F. (1990). Extraversion and happiness. Personality and Individual Differences, 11, 1299-1306.

Rammstedt, B., \& John, O. P. (2007). Measuring personality in one minute or less: A 10 -item short version of the Big Five inventory in English and German. Journal of Research in Personality, 41, 203-212.

Roberts, B. W., Walton, K. E., \& Viechtbauer, W. (2006). Patterns of mean-level change in personality traits across the life course: A meta-analysis of longitudinal studies. Psychological Bulletin, 132, 1-25.

Srivastava, S., John, O. P., Gosling, S. D., \& Potter, J. (2003). Development of personality in early and middle adulthood: Set like plaster or persistent change? Journal of Personality and Social Psychology, 84, 1041-1053.

Staudinger, U. M. (2000). Viele Gründe sprechen dagegen, und trotzdem geht es vielen Menschen gut: Das Paradox des subjektiven Wohlbefindens [Many reasons speak against it, yet many people feel good: The paradox of subjective well-being]. Psychologische Rundschau, 51, 185-197.

Staudinger, U. M. (2001). Life reflection: A social-cognitive analysis of life review. Review of General Psychology, 5, 148-160.

Steel, P., Schmidt, J., \& Shultz, J. (2008). Refining the relationship between personality and subjective well-being. Psychological Bulletin, 134, $138-161$.

Suh, E., Diener, E., \& Fujita, F. (1996). Events and subjective well-being: Only recent events matter. Journal of Personality and Social Psychology, 70, 1091-1102.

Veenhoven, R. (1994). Is happiness a trait? Tests of the theory that a better society does not make people any happier. Social Indicators Research, 32 101-160.

Vittersø, J., \& Nilsen, F. (2002). The conceptual and relational structure of subjective well-being, neuroticism, and extraversion: Once again, neuroticism is the important predictor of happiness. Social Indicators Research, 57, 89-118.

Watson, D., \& Clark, L. A. (1992). On traits and temperament: General and specific factors of emotional experience and their relation to the five-factor model. Journal of Personality, 60, 441-476.

Zautra, A. J., \& Reich, J. W. (1983). Life events and perceptions of life quality: Developments in a two-factor approach. Journal of Community Psychology, 11 121-132. 